\title{
RESTITUCIÓN, REPATRIACIÓN Y NORMATIVA ÉTICA Y LEGAL EN EL MANEJO DE RESTOS HUMANOS ABORÍGENES EN ARGENTINA
}

\author{
Natalia Paola Cosmai ${ }^{1}$, Guillermo Folguera ${ }^{2}$, Delia Outomuro ${ }^{3}$
}

Resumen: El presente trabajo tiene como objetivo analizar el ayer y el hoy del manejo de los restos humanos de comunidades aborígenes. Con este fin, se indagan los casos de tres museos argentinos que, a través de la historia, fueron adoptando distintas posturas y políticas respecto al tema: el Museo de Ciencias Naturales de La Plata, El Museo Ambrosetti, las Momias de Llullaillaco, así como las normativas legales y éticas concernientes al tema. El objetivo último del trabajo es llamar a la reflexión sobre temas como la restitución, la repatriación de restos humanos y el reconocimiento de los derechos de los pueblos originarios.

Palabras clave: restitución, repatriación, ética

Restitution, repatriation, and legal and ethical normatives in handling aboriginal human remains in Argentina

\begin{abstract}
This paper analyzes previous and current practices in handling human remains from aboriginal communities. The cases of three Argentinian museums are analyzed which adopted different practices throughout history: Natural Sciences Museum of La Plata, the Ambrosetti Museum, the Llullaillaco mummies, along with ethical and legal norms. The ultimate goal of the work is to draw attention to topics such as restitution, repatriation and the recognition of the rights of aboriginal peoples.
\end{abstract}

Key words: Restitution, repatriation, ethics

\section{Restituição, repatriaçáo e norma ética e legal no manejo de restos humanos arborígenes na Argentina}

Resumo: O presente trabalho tem por objetivo analisar o ontem e o hoje do manejo dos restos humanos de comunidades arborígenes. Com esta finalidade, são questionados os casos de três museus argentinos que através da história foram adotando distintas posturas e políticas a respeito do tema: o Museu de Ciências Naturais da Plata, o Museu Ambrosetti, as Múmias de Llullaillaco, assim como as normas legais e éticas concernentes ao tema. O objetivo último do trabalho é chamar a reflexão sobre temas como a restituição, a repatriação de restos humanos e o reconhecimento dos direitos dos povos originários.

Palavras-chave: restituição, repatriação, ética

\footnotetext{
${ }^{1}$ Docente del departamento de Humanidades Médicas, Facultad de Medicina, Universidad de Buenos Aires, Argentina Correspondencia: nataliacosmai@hotmail.com

${ }^{2}$ Investigador adjunto CONICET, docente del departamento CEFIEC, FCEN, Universidad de Buenos Aires, Argentina

${ }^{3}$ Coordinadora Unidad Académica Bioética, Directora del Instituto de Bioetica, Facultad de Medicina, Universidad de Buenos Aires, Argentina
} 


\section{Introducción}

Las numerosas expediciones realizadas en nuestro país hacia tierras que habían sido habitadas - $\mathrm{y}$ que incluso aún hoy continúan siéndolo- por pueblos aborígenes, incluyeron en muchos casos la extracción y apropiación de restos humanos de los mismos(1). Luego de esta sustracción, el destino de los restos fue diverso, siendo uno de los principales las vitrinas de museos en diferentes lugares del mundo. Sin embargo, en las últimas décadas han surgido diversas posiciones y argumentaciones respecto de a quiénes corresponde efectivamente poseer dichos restos.

En particular, en nuestro país esta disputa ha ocupado un importante espacio legal a partir de la consideración de los derechos de las comunidades nativas como derechos humanos básicos. En este contexto, resulta imperiosa la discusión ética acerca del rol que deben tener las comunidades de los pueblos originarios en la gestión, manejo y elección de lugar de reposo de los restos de sus antepasados, así como respecto de la legitimidad ética de que dichos restos sean expuestos en museos. En la próxima sección ahondaremos en los marcos éticos y legales vigentes, tanto los referidos al estatus que les es otorgado desde el Estado argentino, como desde la perspectiva de los propios antropólogos y de los museos. Con este fin, se analizan tres casos emblemáticos argentinos, así como los principales agentes sociales involucrados, tratando de reconocer sus posiciones frente a este problema y el tipo de argumentación sobre las que se apoyan para obtener cierta legitimidad. Finalmente, realizaremos una reflexión crítica sobre el problema analizado, considerando todos los elementos reunidos.

Marcos legales involucrados: Estado, arqueólo-
gos y museos

\section{Marco legal del Estado argentino}

En primer lugar, la Constitución Nacional establece en su artículo número 75 , inciso 17 , que el Congreso de la Nación “... reconoce la preexistencia étnica y cultural de los pueblos indígenas argentinos, garantizando el respeto a su identidad
(...), reconociendo la personería jurídica de sus comunidades, la posesión y propiedad comunitarias de las tierras que tradicionalmente ocupan y regulando la entrega de otras aptas y suficientes para el desarrollo humano, siendo ninguna de ellas enajenable, transmisible ni susceptible de gravámenes o embargos, y asegurando su participación en la gestión referida a sus recursos naturales y a los demás intereses que los afecten" (2).

Mediante la Ley No 24.071, fue aprobado el Convenio 169 de la Organización Internacional del Trabajo (OIT) sobre Pueblos Indígenas y Tribales en Países Independientes, que establece que los Estados Miembros deben garantizar una amplia participación de las comunidades indígenas en todos los asuntos que los atañen, incluyendo los aspectos culturales y el respeto a sus tradiciones, creencias y costumbres. Asimismo, la Secretaría de Cultura de la Presidencia de la Nación resolvió que el Código de Ética del ICOM fuera adoptado por la República Argentina, estableciendo en su capítulo III, titulado "Conducta profesional", punto 6, "Responsabilidades profesionales respecto de las colecciones", especificaciones sobre "los restos humanos y piezas con carácter sagrado" (3).

\section{Marco legal de los profesionales}

Respecto del marco legal correspondiente a la práctica profesional, en el Congreso Mundial de Arqueología, de 1990, se alcanzó el denominado "Acuerdo de Vermillion", en el que científicos y pueblos indígenas establecieron lineamientos éticos en relación con el tratamiento de restos humanos indígenas. Estos acuerdos fueron sintetizados en seis puntos, entre los que se destacan, para nuestros fines: 1) Se respetarán los restos humanos de los muertos cualesquiera sea su origen, raza, religión, nacionalidad, costumbres o tradición, 2) Se respetarán los deseos dispuestos por los muertos siempre que sea posible, razonable y legal, cuando los mismos sean conocidos o razonablemente deducidos, 3) Se respetarán los deseos de la comunidad local y de los parientes o guardianes de los muertos, 4) Se respetará el valor de la investigación científica de esqueletos, momias y otros restos (incluyendo fósiles de homínidos) cuando se demuestre que existe tal valor, 5) Sobre la disposición de fósiles, esqueletos, 
momias y otros restos, se alcanzarán acuerdos por negociación basados en el respeto mutuo de los intereses de las comunidades para la disposición apropiada de sus ancestros y de los legítimos intereses de la ciencia y la educación, y 6) El expreso reconocimiento de los intereses de distintos grupos étnicos, así como los científicos, son legítimos y serán respetados, lo que permitirá alcanzar acuerdos aceptables y honorables(4).

A su vez, en la ciudad de Salta, el año 2007, se formula la Declaración de la Asociación de Antropología Biológica Argentina (AABA) en relación con la ética del estudio de restos humanos. En la misma se indica: "Que el estudio científico de los restos biológicos humanos es de interés para toda la humanidad", a la vez que, "5) resulta necesario y deseable facilitar la restitución de restos de identidad conocida (...) a las comunidades de pertenencia que los reclamen, siendo materia de discusión y análisis particular el caso de reclamos de restitución de otros restos. Tal discusión y estudio deben ser efectuados en un marco de mutuo respeto, razonabilidad y acercamiento de perspectivas entre las partes involucradas en la negociación", y "6) Que es recomendable atender a reclamos de no exhibición pública de restos humanos realizados por las comunidades de pertenencia que así lo soliciten"(5).

Finalmente, la Asociación de Arqueólogos Profesionales de la República Argentina, en septiembre de 2009, promulga su Código de Ética Profesional, haciendo referencia al tema tratado en el apartado "De los deberes para con el patrimonio arqueológico", citando en su inciso 8: "Los restos humanos involucrados en investigaciones arqueológicas deben ser tratados con respeto"(6).

\section{Marco legal de los museos en relación con los restos arqueológicos}

En lo que a Argentina concierne, el marco legal cuenta con la ley 25.517, sancionada en 2001. Ella establece que: "Los restos mortales de aborígenes, cualquiera fuera su característica étnica, que formen parte de museos y/o colecciones públicas o privadas, deberán ser puestos a disposición de los pueblos indígenas y/o comunidades de pertenencia que lo reclamen" (art.1). Citando en el artículo 2: "Los restos (...) que no fueren reclamados por sus comunidades podrán seguir a disposición de las instituciones que los albergan, debiendo ser tratados con el respeto y la consideración que se brinda a todos los cadáveres humanos" (art. 2)(7). Unos años después, mediante el decreto 701/2010, se asignó al Instituto Nacional de Asuntos Indígenas como el encargado de coordinar, articular y asistir en el seguimiento y estudio del cumplimiento de las directivas y acciones dispuestas por la ley mencionada(8).

A su vez, el Código de Ética Profesional de International Council of Museums establece que el museo tendrá que responder con diligencia, respeto y sensibilidad a las peticiones de que se retiren de la exposición al público restos humanos o piezas con carácter sagrado, respondiendo de la misma manera a las peticiones de devolución de dichos objetos.

Ahora bien, presentadas las principales legislaciones involucradas respecto a la extracción, conservación y exposición de restos de cuerpos humanos de comunidades originarias, el objetivo de la siguiente sección es reseñar brevemente tres de los principales casos que se han dado en nuestro país y que nos permitirán posteriormente realizar un análisis más general.

\section{Tres casos emblemáticos}

\section{Museo Etnográfico Ambrosetti}

El Museo Etnográfico J. B. Ambrosetti (MEA) cuenta con una de las mayores y más antiguas colecciones de restos humanos en el país, forma$\mathrm{da}$ por las colecciones generadas por el propio MEA y aquellas que en 1947 heredó del Museo Argentino de Ciencias Naturales Bernardino Rivadavia (MACNBR). Las colecciones se dividen actualmente en tres categorías y están guardadas en depósitos separados: Etnografía, Antropología Física y Arqueología. Es la sección de Antropología Física la formada principalmente por restos humanos indígenas, tratándose de una colección deteriorada y en gran parte desconocida, ya que el proyecto de realizar su inventario minucioso se 
inició recién en 2007.

A partir del análisis de sus memorias se puede deducir que en los primeros años del Museo casi todos los restos humanos provinieron de las excavaciones arqueológicas realizadas por la Facultad de Filosofía y Letras, identificados con nombres de individuos africanos, asiáticos y europeos, pero no indígenas americanos, a diferencia de lo que sucede en el caso del Museo de Ciencias Naturales de La Plata. De esta manera, la repatriación y restitución de restos por parte del museo se hacía más difícil. Aún así, en mayo de 2004 el MEA repatrió un toimoko - una cabeza momificada y tatuada como un guerrero maorí- al National Museum of New Zealand Te Papa Tongarewa. La iniciativa partió del Director del MEA, Pérez Gollán, cuando el embajador de Nueva Zelanda en Argentina visitó el Museo en 2003. Esta cabeza fue ingresada al catálogo en 1910, como parte de una colección mayor. Fue esta acción la que demostró la política de repatriación y restitución de restos humanos, acompañada por la política llevada a cabo por el mismo Museo que manifiesta la no exposición de restos humanos. El MEA se convierte, de esta manera, en pionero en llevar adelante esta política de repatriación y restitución de restos aborígenes.

\section{El Museo de Ciencias Naturales de La Plata}

Abierto en 1888 y cuya construcción finalizó en 1889 , se caracteriza por poseer colecciones de Zoología, Entomología, Botánica, Arqueológicas y Etnográficas. Entre estas últimas se destacan los restos humanos y objetos provenientes de Perú y Argentina. En el inventario del museo se puede leer, por ejemplo:

- Esqueleto 1769, "Petizo", toba, Resistencia (Chaco), fusilado en 1886 por orden del coronel Obligado, Colección Spegazzini.

- Esqueleto 1786, "Michel", indio araucano (masculino), CorpenAiken (territorio de Santa Cruz), muerto en 1888 por expedición del Museo.

- Esqueleto 1837, "Sam Slick”, asesinado en Rawson, Chubut. Desenterrado por el doctor F. P. Moreno, viaje 1876-1877.

El inventario, publicado en 1910, supera las cinco mil piezas, incluyendo esqueletos, cráneos, cueros cabelludos, cerebros, mascarillas mortuorias, huesos sueltos y cadáveres disecados.

Muchos fueron saqueados de cementerios indígenas. Otros corresponden a víctimas de la "Campaña al Desierto" o fueron asesinados por expediciones organizadas desde el propio Museo. Algunos estuvieron cautivos, fueron vejados y murieron en el edificio del Bosque platense.

Para nuestros fines, centrémonos en uno de los casos que ha sido objeto de un gran análisis: el del cacique Inacayal. En un principio, este aborigen mantuvo tratos cordiales con exploradores que recorrieron la Patagonia, incluido Francisco Perito Moreno. La situación cambió hacia 1884, cuando el Estado argentino decidió "conquistar el desierto". En octubre, el grupo encabezado por Inacayal y Foyel fue atacado. Treinta murieron y los demás terminaron prisioneros. Según el Centro Mapuche Tehuelche de Chubut, una vez allí fueron disgregados: los niños regalados a distintas familias porteńas, las mujeres destinadas a trabajar como domésticas y los hombres enviados a la isla Martín García a picar adoquines para las calles de las ciudades. En 1886, Francisco P. Moreno gestionó un nuevo sitio para los caciques: el Museo de La Plata. Por las gestiones del mismo fueron recluidos en el edificio del Bosque platense el cacique Inacayal y su mujer, mientras parte de su comunidad lentamente fue muriendo. Varios diarios se hicieron eco de la matanza. El Eco de Córdoba, asociado a grupos católicos, acusó a Moreno de "caballero de la noche". Un periódico porteño, $L$ 'Operaio Italiano, lo cuestionó por no respetar las disposiciones municipales acerca del tratamiento que debía darse a los muertos. Inacayal murió el 24 de septiembre de 1888 y de inmediato su esqueleto descarnado, su cerebro y su cabello fueron incorporados a la macabra colección de los "últimamente vencidos".

El Museo tuvo cautivos a indígenas vivos hasta septiembre de 1894, cuando murió el joven yamana Maish Kenzis, que lleva más de un siglo en una vitrina. No obstante, el paso del tiempo también produjo cambios en las exhibiciones. Ya en 1927, cuando aún se exponían en una vidriera 
central cien esqueletos de originarios, se habló de un "panteón" de "héroes autóctonos que defendieron el suelo patrio de la pampa".

Otro cambio institucional importante se produjo en los años 40, cuando la exhibición dejó de ser masiva. En los 70, los reclamos de restitución se hicieron públicos, en varias partes del mundo. El primer pedido indígena fue en 1988: el Centro Indio Mapuche Tehuelche de Chubut pidió la devolución de Inacayal. El órgano máximo de la Universidad denegó la petición. Recién en abril de 1994 los restos de Inacayal fueron trasladados al valle de Tecka, en medio de actos protocolares, rituales indígenas y discursos políticos en cada parada. Ese mismo año, el 22 de junio, la institución del Bosque restituyó los restos de Panquitruz Güora a la localidad pampeana de Leuvucó. Su cráneo, envuelto por la bandera del pueblo ranquel, recibió homenajes durante todo el recorrido hasta su pueblo. Una representante del Consejo de Lonkos advirtió: “...la verdadera lucha no se termina, porque los demás hermanos que quedan acá pronto van a ser recuperados para que todos puedan descansar en paz”.

\section{Los niños de Llullaillaco}

Durante 1999 se lleva a cabo una expedición a Llullaillaco, Salta, codirigida por el arqueólogo estadounidense Reinhard y la arqueóloga argentina Constanza Ceruti. Dicha expedición estuvo organizada por el Consejo de Expediciones de la National Geographic Society, de Washington, EE.UU., y se llevó a cabo con montañistas y arqueólogos argentinos y peruanos.

El 15 de marzo de 1999, a una altura de 6.700 msnm, casi en la cima, aparecieron tres figuras de llamas, dos de concha marina y una de plata, constituyéndose en el primer hallazgo realizado en el lugar de ofrendas de la cima. Medio metro más abajo se encontraba el primer cuerpo. El 17 de marzo se halló el cuerpo de "El Niño", ese mismo día unos metros más al norte Mercado y Perea hallaron a "La Doncella". Dos días después, fue encontrada la tercera momia, "La Niña del Rayo". Se encontraban acompañando los restos humanos, réplicas en pequeña escala de objetos de uso cotidiano en las comunidades aborígenes, tocados de plumas, arreglos textiles, etc. Se cree que los niños debían transformarse simbólicamente en las figuras que los acompañaban para su viaje. Estos niños-dioses, en su calidad de huacas o posibles mensajeros de los dioses, fueron los seres humanos que estuvieron más próximos al Sol, divinidad del imperio incaico.

A partir de que un sacrificio como este es realizado en la montaña, ésta se sacraliza, queda impregnada de un gran significado religioso, social y político, sus fuerzas se magnifican y sus beneficios redundan en toda la población que la tiene como huaca. El padre del niño sacrificado era agraciado por el Inca, y ascendido a una mayor jerarquía junto con su gente y descendientes futuros. Cinco años después del hallazgo se hizo posible la exhibición al público de una parte del mismo, en el Museo de Alta Montaña de la Ciudad de Salta, creado a tal fin en la ciudad capital de la provincia de Salta.

\section{Agentes involucrados, argumentaciones y legi- timidades}

Argumentos de las comunidades de los pueblos originarios

La problemática que aquí abordamos presenta en nuestro país una multiplicidad de agentes sociales involucrados. Sin embargo, nos centramos aquí en tres de ellos: las comunidades de los pueblos originarios, los arqueólogos y los representantes de los museos de nuestro país. Ser capturados para su exposición con vida, las expediciones llevadas a cabo para su "caza", las masacres ejecutadas durante la Campaña del Desierto, son algunos de los abusos que violentaron el curso de esas vidas y, posteriormente, de sus muertes, por lo que la restitución de los restos de sus antepasados es concebida como un acto de justicia. Más aún, desde esta perspectiva, la devolución de dichos restos a sus descendientes directos $y / o$ indirectos es considerado como un acto de "reparación histórica". Los elementos cuestionados por las comunidades en torno al manejo de restos involucran diferentes aspectos. Por ejemplo, para el caso particular de los niños de Llullaillaco se señalan: 
- La forma en que fue llevada a cabo la extracción de los restos.

- La profanación de un sitio sagrado.

- El hecho de que, para las comunidades de procedencia de los mismos, los niños no se encontraban muertos, sino hibernando.

- El reclamo económico. Esto involucra tanto el de generar un lucro económico mediante la exposición como la falta de participación de los pueblos originarios involucrados(9).

\section{Argumentos de los representantes de los museos}

Respecto de los representantes de los museos, no resulta sencillo comprender ni unificar los elementos legitimadores de su discurso. Por ello, conviene recordar lo señalado por el Código de Deontología del ICOM para los museos en el plano internacional. Dicho código no pretende reemplazar a las propias legislaciones, sino: "que (...) pueda servir a cada país, así como a las organizaciones especializadas vinculadas a los museos, como elemento de referencia para elaborar normas adicionales". Por ello, pretendemos aquí tratar de entender algunos de los elementos de su discurso que actúan como legitimadores de la práctica de los museos y su relación con una perspectiva ética. En particular, nos detendremos brevemente en los ítems 1, 2, 3 y 6. El primer ítem señala que: "Los museos garantizan la protección, documentación y promoción del patrimonio natural y cultural de la humanidad", para luego aclarar que: "Los museos son responsables del patrimonio natural y cultural, material e inmaterial" (3).

Es muy interesante este aspecto por lo que plantea, pero también por lo que oculta. Por un lado, se manifiesta positivamente acerca de si cumplen efectiva y exitosamente dicho trabajo. La pregunta previa es cómo se obtiene la legitimidad para que sean los museos los cuidadores, evidentemente respondida en los siguientes ítems analizados. Pero también es muy interesante lo que oculta: el planteo de que solo los museos pueden lograr tal cuidado.

El segundo ítem marca que: "Los museos que po- seen colecciones las conservan en beneficio de la sociedad y de su desarrollo". Al respecto, luego aclara: "La misión de un museo consiste en adquirir, preservar y poner el valor sus colecciones para contribuir a la salvaguarda del patrimonio natural, cultural y científico". Sin duda, se trata de una legitimidad que actúa complementando el ítem anterior. La tarea de los museos es ofrecer un cuidado que no persigue su propio beneficio sino el de terceros, el de la sociedad como un conjunto. Así, el estudio de los cuerpos involucrados es además un objeto de gran importancia para el estudio científico, un estudio de carácter global e imprescindible desde el discurso actual. En este sentido, el tercer ítem es la explicitación de este aspecto: "Los museos poseen testimonios esenciales para crear y profundizar conocimientos". Este aspecto, además, muestra el modo desde el cual el discurso generado desde los museos se articula con el arqueológico profesional: "salvaguardando" e "indagando" es que puede generarse conocimiento fundamental para la propia sociedad.

El último punto que deseamos presentar señala: "Los museos trabajan en estrecha cooperación con las comunidades de las que provienen las colecciones, así como con las comunidades a las que prestan servicios". Luego complementa indicando: "Las colecciones de un museo son una expresión del patrimonio cultural y natural de las comunidades de las que proceden y, por consiguiente, no solo rebasan las características de la mera propiedad, sino que además pueden tener afinidades muy sólidas con las identidades nacionales, regionales, locales, étnicas, religiosas o políticas". Se incorpora aquí el tercer agente que hemos presentado: los pueblos originarios. La aclaración es central en la medida en que reconoce que no es un mero objeto el que está en disputa, sino que se trata de un componente central en la identidad de cualquier pueblo. De este modo, desde la posición de los museos se trata de un cuidar un patrimonio de la humanidad. Por ejemplo, en algunos casos su restitución al lugar en el que fueron encontrados los dejaría expuestos a posibles sustracciones y posteriores ventas a coleccionistas privados. Se señala entonces que no se persigue otro fin que el beneficio colectivo, no 
pudiéndose lucrar con esto. Finalmente, es reconocida la importancia de tratarlos con el "respeto" correspondiente.

\section{Deteniéndonos en los argumentos involucra- dos}

Cabe realizar a continuación un análisis respecto de las diferentes argumentaciones utilizadas. Uno de los aspectos sin duda relevantes es qué se entiende por el carácter de valor universal de los restos. En una primera aproximación, parece referirse a un valor intrínseco (por lo que es y/o por lo que puede dar), con una importancia que trasciende el límite de las valoraciones particulares de cada cultura. Sin embargo, podría señalarse que este valor nada implica sobre qué hacer una vez éste adjudicado. Sin embargo, desde la argumentación, aquí reside uno de sus pilares argumentales. Por un lado, uno de los aspectos ofrecidos por los museos es el de mostrar dichas piezas. $\mathrm{Su}$ importancia radica en que, dado que lo que es mostrado es un bien en sí mismo, que merece (y debe) ser compartido, encuentra allí su propia legitimidad. Por oposición, la entrega de las piezas a las propias comunidades indígenas, que son sus descendientes, amenazaría no el supuesto carácter público (pues una gran parte de los museos son de hecho privados), sino más bien cierto carácter oculto y, por ende, generarle así una pérdida a la humanidad. El otro pilar argumental tiene que ver con la conservación de dichas piezas, con el estado de su conservación. Eso que no estará visible quedará a su vez expuesto al deterioro.

Es entonces en esta doble fórmula (visible y preservado) que encontramos la principal legitimidad de los museos. Si estas piezas son deterioradas y ocultas, entonces la humanidad toda (incluyendo las propias comunidades involucradas) tendrá una pérdida. Sin embargo, el problema de esta argumentación es que dichos pilares muestran además numerosos inconvenientes. Veamos qué sucede con dicho mostrar. En "nuestra" cultura se espera que los cadáveres posean nombre, apellido y descendencia, sin duda distan de ser "mostrados" para ser ocultos. Reconocido ello, ¿qué justifica esta visibilidad? ¿Su valor universal alcanza para ello? ¿Acaso ese mostrarse (o no) no cabe como uno de los derechos de sus propios descendientes, tal como en nuestra propia cultura? ¿Cómo ese mostrarse podría evadir el propio permiso de ser descendientes directos o indirectos? Ya volveremos a esto, pero veamos un poco mejor el conservar. Es muy interesante como aquí surgen elementos de nuestra tecnocultura, en la medida en que los artefactos tecnológicos son incluidos con fines comparativos y cuantificables. Otro aspecto significativo es que, aún negando el sentido propio en el que la otra cultura le da al cuerpo en cuestión, en nuestra "propia" cultura los restos de nuestros descendientes no tienen el fin de su mayor permanencia inalterable. Como vemos, la legitimidad de este conservar no se extrae de los valores del otro ni tampoco de la extrapolación de los valores de nuestra propia cultura. Es ahí en donde su "valor universal" parece cumplir un rol significativo.

El carácter de valor universal parece ser el modo que tiene nuestra cultura de querer recuperar al otro. No se trata de una mera asignación de los valores propios, pues como hemos visto ni el mostrarse ni el permanecer de los cuerpos de nuestros ancestros aparecen dentro de nuestras propias valoraciones y objetivos. Tampoco, obviamente, del reconocimiento de valores del otro. Se trata más bien de una "restitución" del sujeto que representa el otro, que tiene como "precio" justamente el de mostrarse y permanecer. De hecho, la exposición de alguna manera podría cumplir dos roles sociales diferentes: la muestra del poderoso, pero también la muestra de la barbarie de quien negó al otro. Sin embargo, lejos se está de este segundo rol, en la medida en que la restitución del otro (a partir de que le otorgo valor y, más aún, valor universal) conlleva a un silenciamiento respecto a qué destino darle a esos cuerpos. Quizás este aspecto del interrogante, de un interrogante genuino, sea el aspecto clave. Y, en efecto, esto está sintonía tanto con el código legal de los antropólogos ("Se respetarán los deseos de la comunidad local y de los parientes o guardianes de los muertos"), como con la ley 25.517 ("Los restos mortales de aborígenes, cualquiera fuera su característica étnica, que formen parte de museos y/o colecciones públicas o privadas, deberán ser puestos a disposición de los pueblos indígenas y/o comunidades de pertenencia que lo reclamen"). 


\section{Apuntes finales}

El análisis desarrollado presenta al final de nuestro recorrido ciertas particularidades en los casos analizados. En el caso de los nińos de Llullaillaco, los reclamos por parte de las comunidades aborígenes se han centrado principalmente en un punto clave, que es el hecho de que la extracción de los cuerpos de los niños constituye un hecho de profanación. Como hemos visto, diferentes sistemas legales avalan dicho reclamo, entre otras, la Constitución Nacional y el acuerdo de Vermillion (1990). En el caso del Museo de La Plata, el eje central del reclamo ha sido la no exposición de los restos humanos y la restitución de los mismos a sus descendientes. Este punto también está contemplado tanto en la Constitución Nacional como en la ley 24071 , siendo más específicos sobre este tema en el acuerdo de Vermillion, entre otros. En el caso del Museo Ambrosetti, poder llevar a cabo lo planteado desde lo legal y las normas y acuerdos éticos que se fueron formulando a lo largo de los últimos veinte años se torna un poco más difícil, ya que la procedencia de sus colecciones es, en su gran mayoría, incierta, por tener su origen fuera de América Latina. Aun así, la política colaborativa en cuanto al cumplimiento de estas normas — relativamente actuales- quedó demostrada para el caso del resto maorí señalado.
A pesar de las posturas encontradas, la política de restitución, repatriación y reentierro de restos aborígenes lentamente parece ir cobrando más fuerza, probablemente porque, finalmente, en las últimas dos décadas se empezaron a oír las voces de sus descendientes, lo que dio lugar a la elaboración de normas legales y, lo que es quizás más importante, llevó a la reflexión ética sobre este tema, donde se ponen a la luz diversas interrogantes: ¿son los restos humanos aborígenes patrimonio de la humanidad? ¿Las excavaciones arqueológicas se justifican en pos del conocimiento científico o son un acto de profanación? ¿Qué papel y qué voz tienen los descendientes de aquellos restos identificables?

Si bien aún persisten posiciones contrapuestas, con los años ha cobrado más fuerza la posición que avala una restitución a los pueblos originarios, tanto en los profesionales como en la sociedad en su conjunto. Probablemente, entre los desafíos aparece el de buscar medidas que apunten a la modificación de políticas estructurales en cuanto al reconocimiento de las comunidades. Éstas debieran incluir un planteo profundo y a conciencia sobre temas como restitución de territorios, reafirmación de derechos, cohesión y fortalecimiento al interior de las comunidades, perfilar identidades y pertenencias sociales. 


\section{Referencias}

1. Castilla A. Criterios sobre exhibición de restos humanos en los museos. Disponible en http://www.cultura.gov.ar [Acceso 2 de junio de 2012].

2. Constitución Nacional Argentina, segunda parte: Autoridades de la Nación, Capítulo Cuarto: Atribuciones del Congreso, artículo 75, inciso 17. 1994. Disponible en http://www.senado.gov.ar [Acceso 20 de junio del 2012].

3. ICOM Organization. 1946-1996 ICOM Chronology, 1996. Disponible en http://www.icom.org/ [Acceso 20 de junio de 2012].

4. South Dakota WAC Inter Congress. The Vermillion Accord on Human Remains. Disponible en http://www. worldarchaeologicalcongress.org/about-wac/codes-of-ethics/168-vermillion [Acceso 2 de junio de 2012].

5. Declaración de la Asociación Antropológica Argentina en relación con la ética en el estudio de restos humanos, 2007. Disponible en http://www.fcnym.unlp.edu.ar/aabra/ [Acceso 25 de junio 2012].

6. Asociación Arqueólogos Profesionales de la República Argentina (AAPRA), 2010; artículo 9. Disponible en http://museosdesantafe.com.ar/ [Acceso 21 de mayo de 2012].

7. Congreso de la Nación Argentina. Ley 25517, Decretos comunidades indígenas, 2001. Disponible en: http:// www.sdh.gba.gov.ar/comunicacion/normativanacyprov/pueblosoriginarios/nacional/nac_ley25517.pdf [Acceso 10 de mayo de 2012].

8. Poder Ejecutivo Nacional. Decreto 701/2010. 2010. Disponible en: http://www.inapl.gov.ar/renycoa/decreto_701.pdf [Acceso 10 de junio de 2012].

9. Betancourt I. El MAAM: un museo para el cadáver de la ética. Salta Libre 2010 [diario virtual]. En http:// www.saltalibre.net/ [Acceso 10 de julio de 2012].

Recibido: 27 de noviembre de 2012

Aceptado: 15 de enero de 2013 